\title{
A lifecycle management system for capital construction facilities based on a digital cloud platform implementing information modeling methods and technologies
}

\author{
Maxim Zheleznov* \\ Moscow State University of Civil Engineering (NRU MGSU), 129337, Moscow, Russia
}

\begin{abstract}
The first is the introduction of information modeling technology (IMT) capital construction facilities (CCF) at all stages of the life cycle (LC), as well as information modeling of urban areas for the tasks of urban building and planning. The second is the digitalization of procedures and services in the field of construction, the formation of unified accessible data sets and information platforms that implement a unified information space for the construction industry. To implement the presented tasks, it is proposed to create a distributed life cycle control system for capital construction facilities (DCS LC CCF) and form a digital cloud platform (digital infrastructure) for the implementation of investment and construction projects based on the use of information modeling technologies, artificial intelligence and predictive analytics.
\end{abstract}

\section{Introduction}

The construction industry currently faces two key digital challenges.

The first is the introduction of information modeling technology (IMT) capital construction facilities (CCF) at all stages of the life cycle (LC), as well as information modeling of urban areas for the tasks of urban building and planning with a significant number of publications devoted to this problem [1-18].

The second is the digitalization of procedures and services in the field of construction, the formation of unified accessible data sets and information platforms that implement a unified information space for the construction industry [19-23].

To implement the key tasks presented above, it is proposed to create a distributed life cycle control system for capital construction facilities (DCS LC CCF) and form a digital cloud platform (digital infrastructure) for the implementation of investment and construction projects based on the use of information modeling technologies, artificial intelligence and predictive analytics, which will allow:

- To develop unified approaches to the management of investment and construction projects based on modern digital information technologies;

\footnotetext{
* Corresponding author: m.zheleznov@mail.ru
} 
- to test existing and new tools and technologies of information modeling in construction for LC CCF management;

- $\quad$ to create an environment of common data necessary and sufficient to use artificial intelligence technology for LC CCF management predictive analytics;

- to assess the economic efficiency and consumer qualities of tools and information modeling technologies in construction used in LC CCF management.

The project is focused on the creation of scientific and methodological foundations for solving information modeling problems at the LC stages of a construction site. Implementation of the LC CCF concept with the use of information modeling is a key and priority task for the economy of the Russian Federation (order of the President of the Russian Federation V.V. Putin dated July 192018 No. PR-1235 on the transition to a capital construction life cycle management system). Development of a methodology for information monitoring and control in management tasks LC CCF is the key to the successful transition of the construction industry to digital management and control methods.

\section{Methods}

\subsection{Research directions}

The key areas of research in the project implementation are:

1) Conducting the experiments in the application of information modeling tools and technologies at LC CCF stages.

2) Conducting scientific research to determine the economic efficiency and prospects of the LC CCF information modeling tools and technologies' implementation.

3) Conducting research in the field of using artificial intelligence technology, using data from the information model of a capital construction facility in order to automate LC CCF stage management.

Within the framework of the project, it is planned to analyze the existing technological processes of construction, regulatory and methodological base. On the basis of the conducted system analysis, to develop a scientific concept of information modeling at various stages of LC.

To link information modeling processes into a single information system, scientific and methodological foundations for data management in information modeling of objects at various stages will be developed. LC CCF, including the development of future requirements for artificial intelligence systems for predictive analytics of construction information.

\subsection{Project roadmap}

STEP 1. DESIGN WORK (2021-2022):

1) Formation of scientific cooperation for the project implementation (Big Data Center of Lomonosov Moscow State University, etc.);

2) Development of technical requirements for computing power and technologies used;

3) Formation of a set of implemented information services and structure of information interaction / communication, development of the digital cloud platform architecture.

STEP 2. THE SYSTEM STRUCTURE DEVELOPMENT AND ITS INFORMATION SUPPORT (2022):

4) Structure development DCS LC CCF (software package)

5) Building the physical infrastructure of a digital cloud platform;

6) Development of the information environment interface for interaction;

RESULT: DCS LC CCF project has been developed and the infrastructure of the digital 
cloud platform has been formed.

STEP 3. SOFTWARE IMPLEMENTATION OF THE SYSTEM AND DEVELOPMENT OF INFORMATION SERVICES (2023):

7) Development of DCS LC CCF (software package);

8) Filling the cloud environment with information services;

9) Determination of regulations and technological solutions for the collective use of cloud infrastructure;

RESULT: DCS LC CCF has been developed and a digital cloud platform with the corresponding regulations for its use has been formed

STEP 4. TEST OPERATION OF THE CCF LIFE CYCLE MANAGEMENT SYSTEM (2024):

10) Implementation of mechanisms of interaction / merger / integration with state information systems;

11) Control LC CCF based on information modeling technologies based on the developed software package;

12) Development of a construction management methodology at all stages of the life cycle of a capital construction facility based on DCS LC CCF.

RESULT: Pilot project for life cycle management of capital construction facilities based on DCS LC CCF has been implemented.

STEP 5. DEVELOPMENT OF ANALYTICAL TOOLS BASED ON THE CCF LIFE CYCLE MANAGEMENT SYSTEM PILOT OPERATION RESULTS (2025):

13) Development of a methodology for assessing the effectiveness of the use of information modeling tools and technologies in construction;

14) Development of a set of tasks for managing an investment and construction project and predictive data analytics of an information model formed at all stages LC CCF based on artificial intelligence technology;

15) Development of an educational and methodological complex for managing the life cycle stages of a construction project object using DCS LC CCF.

RESULT: Methodology for assessing the effectiveness of the use of information modeling tools and technologies in construction. An experimental version of artificial intelligence technology, based on the information model data, formed at all the life cycle stages of a capital construction facility, for predictive analytics and management of an investment and construction project. Educational and methodological complex for managing the stages of the construction project object life cycle using DCS LC CCF.

STEP 6. IMPROVEMENT AND PRACTICAL APPLICATION OF ANALYTICAL TOOLS BASED ON THE CCF LIFE CYCLE MANAGEMENT SYSTEM OPERATION RESULTS (2026-2030):

16) Industrial exploitation DCS LC CCF based on information modeling technologies and on the developed software package;

17) Practical solution of industry-specific tasks of predictive analytics and management of an investment and construction project based on data from information models formed at all LC CCF stages;

18) Improvement of analytical tools for predictive analytics and management of an investment and construction project based on the data from information models formed at all stages LC CCF based on the developed automated system's industrial operation results;

19) Training of industry specialists in managing the construction project object life cycle stages using DCS LC CCF.

RESULT: Artificial intelligence technology based on information model data generated at all stages LC CCF, for predictive analytics and investment and construction project management has been proven. A set of tasks for the practical application of artificial intelligence technology, based on the data of the information model, formed at all stages of 
the life cycle of a capital construction facility have been solved. Highly qualified personnel of the industry with competencies in managing the stages of the life cycle of a construction project object using DCS LC CCF has been trained.

\section{Results}

The immediate result of the project will be:

1 DCS LC CCF (software package), which will provide digital communication and interaction between all participants in the construction process as part of the implementation of the life cycle management concept CCF using information modeling.

2 Methodology of construction management at all life cycle stages of a capital construction facility based on DCS LC CCF has been developed.

3 The pilot project for managing the stages of the life cycle of a construction project object using DCS LC CCF has been implemented.

4 Methodology for assessing the effectiveness of the use of tools and information modeling technologies in construction has been developed.

5 Technology of artificial intelligence, based on the data of the information model, formed at all stages of the life cycle of a capital construction facility, for predictive analytics and management of an investment and construction project has been proven.

Educational and methodological complex for managing the stages of the life cycle of a construction project object using DCS LC CCF has been implemented.

\section{Conclusion}

Building an integrated (continuous) life cycle management system for a capital construction facility requires a special approach to the task of ensuring internal and external interoperability with government information platforms. It is proposed to investigate the possibilities of intelligent information processing methods, technologies and methods for analyzing Big Data to ensure prompt information processing and ensure the interoperability of tasks in information modeling at various stages of the capital construction facilities' life cycle. Further, it is planned to develop methodologies (in fact, a description of pilot technologies) of information monitoring using specialized mobile applications at each stage of a construction object life cycle (pre-design studies and investment feasibility studies, design, construction, operation, demolition / dismantling and disposal), including the development of new methods for collecting and integrating digital information into an information model using big data technologies (Big Data) and the economic efficiency of the developed solutions' further implementation.

To implement the project, it is planned to form scientific cooperation for the implementation of the project by joining the consortium of the Center for the National Technological Initiative on Technologies for the Storage and Analysis of Big Data of the Moscow State University named after M.V. Lomonosov.

The reported study was funded by RFBR, Sirius University of Science and Technology, JSC Russian Railways and Educational Fund "Talent and success", project number 20-38-51013.

\section{References}

1. V. Popov, V. Juocevicius, D. Migilinskas, S. Mikalauskas, Application of building information modelling and construction process simulation ensuring Virtual Project 
Development concept in 5D environment, (ISARC 2008, 25th International Symposium on Automation and Robotics in Construction) (2008)

2. Z. Tan, H. Liu, C. Zeleny, Journal of Mechanical Engineering Research and Developments 38 (1), 105-111 (2015)

3. A. Ginzburg, L. Shilova, A. Adamtsevich, L. Shilov, Journal of Applied Engineering Science 14 (4), 457-460 (2016)

4. A. Volkov, L. Shilova, MATEC Web of Conferences, 05009 (2016)

5. M. Jacobsson, C. Merschbrock, Engineering, Construction and Architectural Management 25 (8), 989-1008 (2018)

6. A.H. Abd Jamil, M.S. Fathi, Built Environment Project and Asset Management 8 (4), 372-385 (2018)

7. S. Jiang, N. Wang, J. Wu, Journal of Computing in Civil Engineering 32(5),04018039 (2018)

8. T. Wang, Tiedao Xuebao, Journal of the China Railway Society 41(1), 1-9 (2019)

9. A. Ginzburg, L. Shilov, L. Shilova, Journal of Physics: Conference Series 1425 (1), 012156 (2020)

10. B. Lee, H. Choi, B. Min, J. Ryu, D.-E. Lee, Automation in Construction 126, 103680 (2021)

11. M. Al Hattab, Journal of Building Engineering 37, 102159, (2021)

12. J.P. Carvalho, L. Bragança, R. Mateus, Computers in Industry 127, 103400, (2021)

13. Y. Shi, J. Xu, Automation in Construction 125, 103611, (2021)

14. I. Bernardino-Galeana, C. Llatas, M.V. Montes, J. Canivell, P. Meda, Springer Series in Geomechanics and Geoengineering, 404-426, (2021)

15. A. Sidani, F.M. Dinis, L. Sanhudo, J. Poças Martins, A. Soeiro, Archives of Computational Methods in Engineering 28(2), 449-462 (2021)

16. Z. Liu, Y. Lu, M. Shen, L.C. Peh, Journal of Cleaner Production 291, 125223 (2021)

17. F. Xue, L. Wu, W. Lu, Advanced Engineering Informatics 47, 101245 (2021)

18. J. Wu, J. Chen, G. Chen, W. Ke, J. Huang, Advances in Civil Engineering 2021, 8884864 (2021)

19. X. Huang, Journal of Physics: Conference Series 1865(3), 032016 (2021)

20. J.P. Xing, E3S Web of Conferences 248,03069 (2021)

21. D. Li, J. Liu, L. Feng, H. Qi, Y.F. Computer-Aided Civil and Infrastructure Engineering 36(4), 453-471 (2021)

22. A.V. Arrotéia, R.C. Freitas, S.B. Melhado, Frontiers in Built Environment 7, 520154 (2021)

23. M. Valinejadshoubi, O. Moselhi, A. Bagchi, A. Salem, Sustainable Cities and Society 66, 102602 (2021) 